\title{
Research on E-commerce Strategy of Agricultural Products of Our Province under the Background of "Internet Plus"
}

\author{
Zhihe Wang
}

Hunan University of Humanities, Science and Technology,Loudi,Hunan,417000,China

\begin{abstract}
Internet+" has become increasingly fierce. Various industries are facing a new situation in market development and strengthening the use of Internet platforms in order to seize the opportunity to complete the transformation and development of enterprises under the momentum of the Internet. Creating an ecological economy in a new field and strengthening the full integration of the agricultural industry and the Internet is a general trend. Taking the fresh agricultural products in Hunan Province as an example, the thesis analyzes the e-commerce strategies of our province under the background of internet, and expects to find an accurate way to develop the e-commerce of agricultural products in the context of the Internet.
\end{abstract}

Keywords: "Internet+"; Agricultural products; E-commerce.

\section{Introduction}

The issue of agriculture, rural areas, and farmers is currently the focus of the Central Government. Under the current fierce competition in the international market, how to promote faster and better development of agriculture and improve the overall strength and overall quality of the agricultural product industry chain are issues that need to be considered in current agricultural development. With the development and popularization of the Internet and wireless networks, the development of ecommerce with B2B and B2C is in full swing. In 2014, the transaction volume of China's e-commerce online shopping market reached 2.42 trillion yuan, a growth rate of $31.5 \%$. Compared with 2013, the growth rate slowed, and the growth rate decreased by $7.9 \%$, but the growth rate remained. Faster. In 2014 , the online shopping turnover accounted for $9.1 \%$ of the total retail sales of consumer goods in the society, an increase of $1.2 \%$ compared to 2013. As of 2015, China's e-commerce transaction volume has exceeded 13.5 trillion yuan, and China's Internet e-commerce users exceeded 500 million. According to the above data, e-commerce has become an effective channel for product marketing today. Similarly, the success of e-commerce can be replicated on agricultural products.

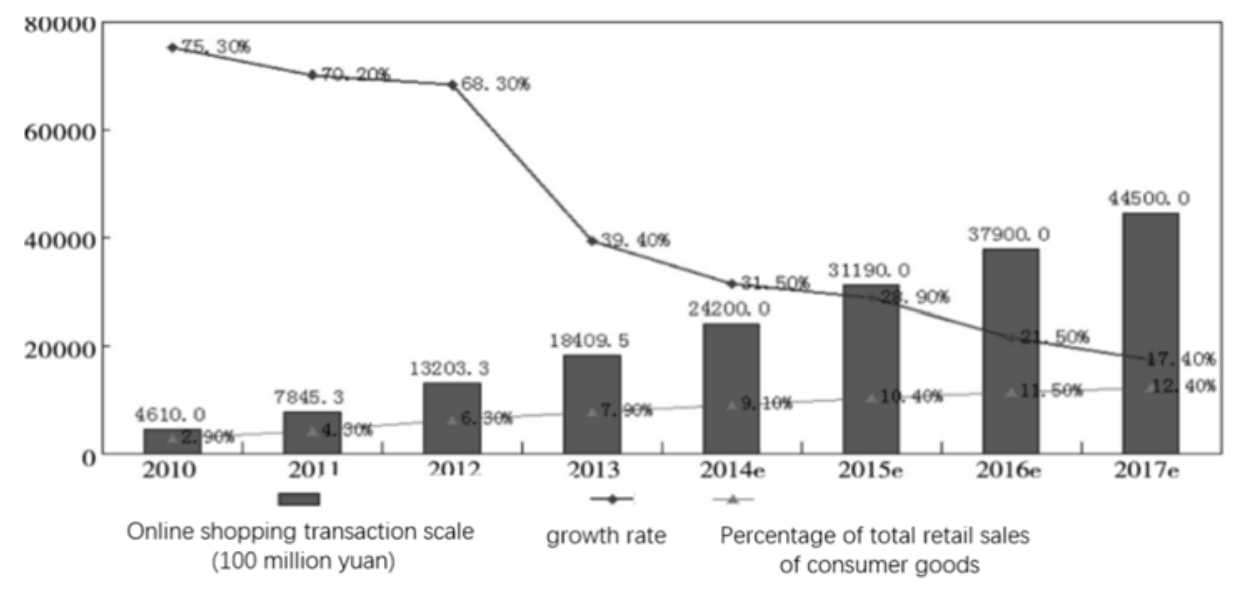

Fig. 1 China's online shopping transaction volume from 2010 to 2017

\section{Feasibility Analysis of Establishing E-commerce Platform for Agricultural Products in Hunan Province}

Hunan Province, as a large agricultural province, under the various forms of e-commerce, such as agricultural e-commerce, rural business information services, and "agricultural super-docking," has 
achieved a leading position in e-commerce development and construction in China, breaking the inherent nature of rural areas. The closed economy.

First, Hunan Province is located in a favorable area in central China and has convenient aviation, railway, and road transportation. It builds an effective transportation network for the transportation of agricultural products. At the same time, Hunan Province itself is a large agricultural province. It produces and transports a large number of agricultural and sideline products each year. It is also one of the supply bases for pollution-free fresh agricultural products in China[1].

Secondly, the Hunan Provincial Government has given preferential policies for the development of agriculture. Especially after the rise of the e-commerce model, the Hunan Provincial Government pointed out the working ideas of e-commerce in 2016 and proposed to vigorously popularize "Internet specialized agricultural products". The e-commerce model and the strong support of policies have brought new opportunities for the development of e-commerce in Hunan Province.

Third, current online shopping consumers are showing an upward trend year after year, especially for fresh products. Therefore, the potential customer groups for fresh agricultural products ecommerce development in Hunan Province are huge. Compared with the single offline promotion sales, the e-commerce audience groups are even larger.

\section{Analysis of E-commerce Implementation Mode of Agricultural Products in Hunan Province}

\subsection{O2O Mode}

The merchants have opened online stores on the e-commerce platform, displaying product information, including production bases, selling prices, and quality, on the network for buyers to browse and screen. That is, businesses directly face the consumers. After the consumers recognize the agricultural products of the merchants, they can directly make electronic payments on the platform. The products are accepted by the logistics companies and transported to the end users. The consumer experiences and verifies after receiving the goods and conducts an objective evaluation[2]. As the 21 st century online shopping hotspot is no stranger to the above transaction mode, the common network platform is Taobao, Pinduo, Jingdong, Weidian and so on. This model satisfies the diversified needs of consumers, reduces the investment cost of businesses, and also saves consumers time. Agricultural Electronic 020 business model is shown in Figure 2 below.

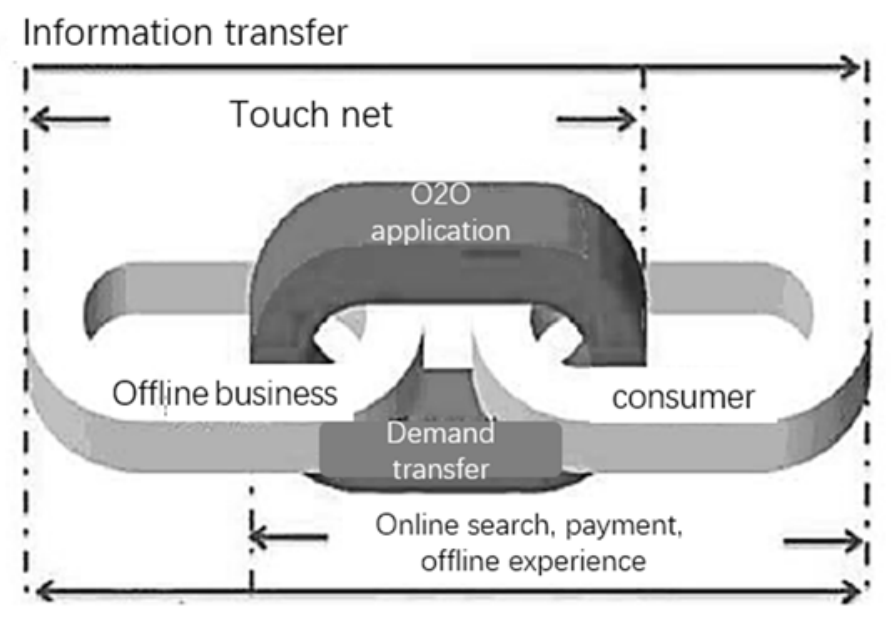

Fig.2 Agricultural e-commerce $\mathrm{O} 2 \mathrm{O}$ mode diagram

\subsection{Information Intermediary Service Model}

Through government departments or agricultural technology management departments, using the Internet model to transmit local agricultural product information to the public, this intermediary model can speed up the smooth flow of information flow, business flow and capital flow, and can 
also avoid the complexity of intermediate links in e-commerce operations. Ultimately, the accuracy and fluency of information transmission are achieved. For example, the village music website, professional counterparts agricultural information and product supply of major agricultural bases, this model is suitable for large distributors to find sources of goods, help a large number of online trading of agricultural products[3].

\subsection{Third-party Trading Model}

The third-party online agency transaction is that the agricultural product supplier submits the product to the intermediary to complete the online sales. The transaction model can increase the product public trustworthiness, and at the same time there is a professional sales software to complete the electronic commerce transaction process. After a third-party transaction, it is possible to gather more agricultural product suppliers with high credit and terminal demanders together, and to promote the brand influence of the three-way trading model of agricultural products e-commerce, as the Fig. 3 shows.

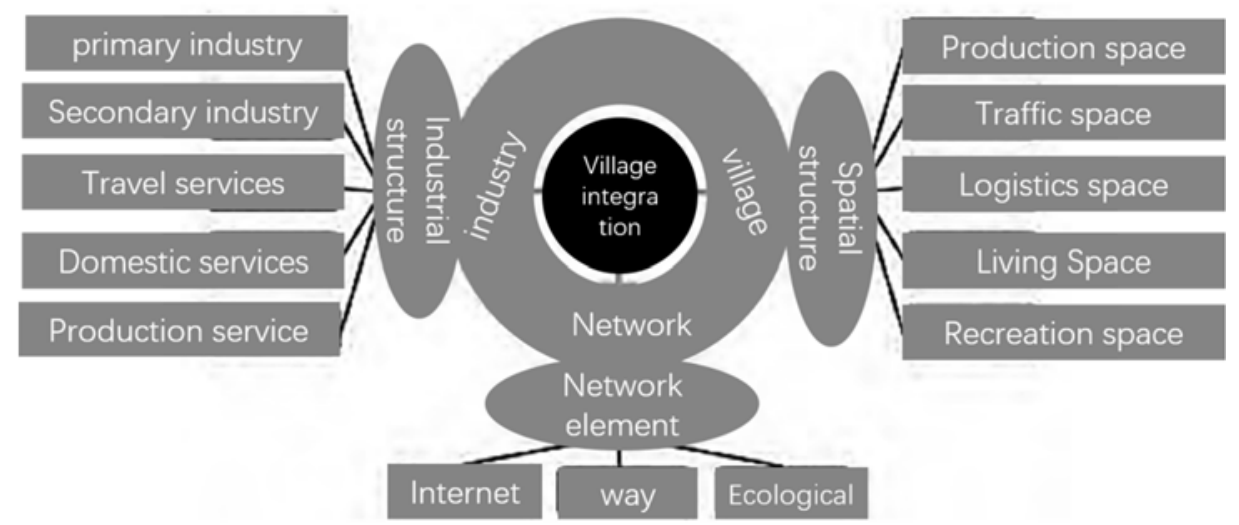

Fig.3 Diagram of agricultural products e-commerce model

\section{E-commerce Platform Under "Internet+" Deepens the Reform of the Agricultural Product Consumer Market from Multiple Perspectives}

Under the "Internet +" technology development background, from the perspective of space, time, cost, security, and personalization, we can deepen and reform Hunan's agricultural product consumption market, gain consumer acceptance, and achieve personalized choice of consumption.

Firstly, "Internet +" broke through the barriers of trading in time and space, transmitting transaction news anytime and anywhere, solving the problem of the information forces of buyers and sellers, and effectively linking the agricultural product supply market. From the perspective of food safety, "Internet + " has built a transparent supply chain, formed a food safety traceability system, and realized the sublimation of the value of agricultural products. For example, the "Internet + " is used by the right-hand KFC to support the chicken market. Using a highly vertical business integration model, each chicken is raised, hatched, slaughtered and processed to form a unified business brand to ensure the food safety of chicken[4].

Secondly, from the product itself, the business platform promotes the sales and circulation of products. The agricultural products in Hunan Province are the same as those in other regions, have a certain seasonality, and have a short shelf life and are prone to decay and deterioration. As for the yellow peach produced by the Yanling County Party Committee, the radiation range of the product is limited, and its liquidity is relatively limited. The county, under the leadership of the county government, innovated marketing methods, changed traditional marketing methods according to market demand, started to enter the e-commerce platform, built Taobao and Alibaba e-commerce platforms, and formed an e-commerce model village. The yellow peach brand in Yanling County was spread all over the country, increasing the sales of farmers and increasing income. 
Thirdly, e-commerce can enhance the brand effect of agricultural products. The e-commerce platform has a wide audience and strong communication, which helps to establish a regional brand image. In addition, consumers conduct agricultural product trading through e-commerce platforms, increasing the brand value of agricultural products and obtaining good results. The brand effect is the added value that non-e-commerce cannot bring. For example, in the fresh supply of a supermarket in Russia, VR visual technology is used to display the feeding process of fresh products in front of consumers, so that consumers can recognize the safety of the fresh products from the bottom of their hearts. The brand effect of the agricultural product is enhanced.

Fourth, the e-commerce platform is not only a platform for one-to-one sales between consumers and farmers, but also a strict quality supervision system. Through the Internet and technical support, the e-commerce system closely links the supply chain links that were originally separated from each other, and supervises and regulates the spot, growth and processing procedures of agricultural products, ensuring the construction of the credit system of fresh agricultural products and further enhancing it. Product quality and safety assurance and good market competitiveness, through the ecommerce information platform, the government departments through the consumer information feedback, effective supervision of green safety of agricultural products. For example, Li Minghua Rural Cooperative, which is a typical representative of ecological agriculture in Hubei Province, has independently developed a breeding model of "planting rice and raising old carp" and developed a platform resource for external mobile internet. Label the QR code, use the collected scan QR code to enter the mobile Internet interface of the agricultural product industry, view the surveillance video of the breeding base, real-time food security commitments, and liability insurance documents, and initiate direct consumer Product stewardship addresses food safety issues from the source.

Finally, from the point of view of personalized consumption, agricultural e-commerce is more adapted to the consumption pattern of individualized demand. Using e-commerce, big data analysis can be conducted on the order sales model of consumers to find consumer preferences and based on consumer preferences. Conduct centralized production and sales. In particular, in recent years, the boom in rural Taobao has caused Taobao to register more than 400,000 agricultural products online stores. The e-commerce platform led by Alibaba will establish 100,000 village-level service stations in major counties in the future. Jingdong plans to add 500 county-level service centers and recruit tens of thousands of rural e-commerce promotion specialists. The establishment of these online stores has provided convenience for meeting the individual needs of consumers.

\section{How does Hunan Province Seize the Opportunity of "Internet +" Development and Establish an E-Commerce Sales Model for Agricultural Products}

\subsection{Encourage Rural Areas to Create Distinctive Brands and Strengthen Large-Scale Operations}

Firstly, make full use of the local characteristics of agriculture, and strive to produce high-quality products that meet the "three products and one standard". Apply standardized operation modes, implement unified and standardized packaging, operations, distribution, and after-sales, strictly control product quality supervision, and strengthen product added value. Well-known build. Secondly, government departments encourage and support the creation of a green pass for the special brands of agricultural products and simplify the approval process for rural projects. The government takes the lead in attracting investment, and actively guides farmers in applying scientific planning concepts to combat illegal production forces from the source. To make product types from sporadic decentralization toward standardized production of systems. At the same time, food safety regulatory authorities need to have a clear division of labor and strengthen the management of fresh agricultural products from the source of production to quality inspection. 


\subsection{Serve the "Internet + Agriculture" Platform to Serve Value-Added Services to Complement Each Other and Help Farmers Increase Their Income}

Relying on the Internet platform as the main carrier of services, closely integrated with market demand, to promote the transformation of "company + farmers" towards "network + farmer households", so that farmers can truly integrate into the industry format of agricultural value-added industries, eliminating middlemen to earn the difference Numerous steps have been taken to resolve the conflict of interests between the company and the farmers and open up more income channels for farmers. The e-commerce platform provides farmers with product trading services and support platform services, which facilitates scaled production and access to the cost leadership of social services.

\subsection{Do a Good Job At Grass-Roots Villages and Villages to Ensure Communication and Relations Between Farmers and Consumers}

The village station is a new force in the e-commerce service system, breaking the solid ice time between farmers and consumers and playing an irreplaceable role in social services. For example, the village village music website, the original purpose is to help farmers get rich in rural product supply and demand, employment and entrepreneurship, rural tourism and other aspects, and promote rural economic development. In addition, the website also took college students as village leaders and village leaders to take the lead in getting rich as the leading group, chose it as the village chief, and provided free wifi and supermarket management systems for rural shops, which effectively solved the big data application service for agricultural products. At the same time, the research and application of agricultural big data has been established, and consumer data has been processed, stored, and analyzed to provide more accurate application services for farmers and to help them choose more efficient models for farm produce cultivation.

\subsection{Retaining Talents and Promoting the Innovation and Reform of the Farmers' Ideological Behavior with Example Power}

Because of the relatively obstructed ideas and ideas in rural areas, it is difficult for them to accept new things. It is necessary to promote the transformation of their ideas and production concepts through the power of role models, and village leaders, university student village officials, and large agricultural producers can be the leaders. To channel it, effectively promote the peasants' ideological thinking changes, and promote its rapid growth. Various governments can allocate corresponding ecommerce training funds, cooperate with colleges and universities, train farmers to participate in the "Internet + agriculture" business skills, cultivate a group of farmers with new occupations, and encourage them to return home to become entrepreneurs. The first group of people with Internet thinking also need to vigorously develop smart terminal classrooms, promote farmers' participation in professional intelligent training through various training methods, realize the intelligentization and mobilization of farmers' training, and promote public entrepreneurship and innovation.

\section{Conclusion}

In the wave of Internet + information, online information and data has become an effective way to reduce costs, increase profits, and expand brand effects. The arrival of the Internet + era not only refreshes people's understanding of the production and sales model, but also realizes that Agricultural consumer e-commerce platform broad consumer audience groups. By discussing the construction of the e-commerce platform for agricultural products in Hunan Province, the author believes that under the Internet + , the sales of agricultural products must keep pace with the development of the times, break out of the bar, and go through e-commerce to a broader platform to truly increase the income of farmers. Promote rural economic growth. 


\section{References}

[1]. Lin Jin. Innovation of Agricultural E-Commerce Development Model in the Internet Age. Journal of Fujiang University, Vol. 1(2017) No. 38, p.29-34.

[2]. Cui junjian, Wang Guohui Internet $\mathrm{O} 2 \mathrm{O}+$ electric business model agricultural development to explore. Chinese New Technology and New Products, Vol.17(2016) No. 15, p.17-20.

[3]. Zhu Yan, Han Xiaoning. Research on e-commerce marketing model of agricultural products under the "Internet+" thinking_-Taking 2015 Yantai Cherry Marketing as an example. Science and Technology Vision, Vol.3(2016) No.22, p.24-38.

[4]. Weng Wenjuan. Agricultural Product Marketing Model Based on E-commerce Platform: Taking Chongqing as an Example. Chinese Journal of Agricultural Resources and Regional Planning, Vol.7(2016) No.37, p.206-210. 